\title{
Educação Ambiental: saberes necessários \\ a práxis educativa docente de uma escola amazônica amapaense
}

\section{Environmental Education: knowledge required for the educational faculty praxis of an Amazon Amapaense school}

\author{
Raimunda Kelly Silva Gomes* \\ Luiza Nakayama**
}

\begin{abstract}
RESUMO
O objetivo deste estudo foi compreender os saberes dos(as) professores(as) da Escola Francisco Filho, na Amazônia amapaense, sobre a inserção da Educação Ambiental (EA) em suas práxis educativas, a partir de uma vertente holística e/ou socioambiental. Para tanto, utilizamos a técnica de entrevistas semiestruturadas e duas sessões de grupo focal, com ênfase numa abordagem qualitativa. Os resultados mostram que os(as) professores(as) sentem receio de implantar projetos e atividades que insiram a EA em suas práticas educativas. Portanto, a EA no contexto escolar deve levar em conta a dinâmica de seus contextos socioambientais e culturais, entendendo os(as) professores(as) como profissionais que têm saberes e concepções construídas na práxis.
\end{abstract}

Palavras-chave: Saberes. Educação Ambiental. Docentes.

\begin{abstract}
The aim of this study was to understand the knowledge of the teachers in the Francisco Filho school, in Amazon forest in the state of Amapá, about the inclusion of environmental education in their educational practice from
\end{abstract}

DOI: $10.1590 / 0104-4060.50459$

* Universidade do Estado do Amapá. Macapá, Amapá, Brasil. Av. Pres. Vargas, nº 650. Central. CEP: 68900-070. E-mail: rkellysgomes@yahoo.com.br

** Universidade Federal do Pará. Belém, Pará, Brasil. Rua Augusto Corrêa, nº 1. Guamá. CEP: 66075-110.E-mail: lunaka@ufpa.br 
a holistic and/or environmental component. To accomplish this, we use the technique of semi-structured interviews and two focus group sessions with an emphasis on qualitative approach. The results show that the teachers feel afraid to implement projects and activities that insert environmental education in their educational practices. Therefore, the environmental education in their school context must take into account the dynamics of their social, environmental and cultural contexts, seeing the teachers as professionals who have knowledge and concepts built in praxis.

Keywords: Knowledge. Environmental education. Teachers.

\section{Introdução}

Atualmente, são necessárias novas visões de mundo, através de uma educação com abordagens didático-pedagógicas diferenciadas, voltada para a construção de uma cidadania planetária, pois educar ambientalmente hoje vai além de sensibilizar a população para os problemas existentes. É preciso o exercício pleno da cidadania em um processo de conscientização (consciência + ação) para exteriorizar em ações aquilo que interiorizamos (razão e emoção) para uma reflexão crítica (TOZONI-REIS, 2008; GUIMARÃES, 2011; TEIXEIRA; TORALES, 2014).

Assim, a EA na formação de educadores assume o desafio de provocar mudanças na vida cotidiana dos indivíduos, dando ressignificação a relação do homem com a natureza e ao seu modo de vida (LEFF, 2010), compreendendo a importância da educação para a cidadania planetária e, consequentemente, para um futuro sustentável.

Sabe-se que a compreensão da EA, pelas vivências dos educadores ambientais, possibilita a constituição da identidade socioambiental e política que consolidam as reflexões cotidianas, de modo que é necessário que o(a) educador(a) compreenda a EA em sua complexidade para a transformação das relações entre sociedade e ambiente.

Para Carvalho (2012), a existência de um sujeito ecológico passa a credibilidade de que é possível um mundo transformado, em que a constituição de uma atitude ecológica concreta possa servir de incentivo para a formação de educadores ambientais. No entanto, Tozoni-Reis (2008) alerta que essa formação é um processo de transmissão de valores e atitudes - por isso a preocupação com a formação cultural -, as quais são os principais indicadores da representação da educação, através da subjetividade humana. 
A EA, quanto tendência educacional, vislumbra inter-relacionar os aspectos ambientais aos educativos, possibilitando uma formação de educadores(as) ambientais que valoriza a diversidade cultural, evidenciada no Programa Nacional de Educação Ambiental (PRONEA), ao considerar a temática meio ambiente fundamental no fazer educativo docente; pois, devem assumir o desafio de abrir caminhos para esse porvir, traçando reflexões sobre o sentido da existência humana.

Para que ocorra a efetivação da EA nas práticas docentes, é preciso considerar que os conhecimentos escolares são decorrentes de um processo de construção social, ao mesmo tempo compartilhados e negociados entre os diversos grupos que compõem esta dinâmica, no qual a temática ambiental, no processo educativo-escolar precisa integrar a prática cotidiana docente (TARDIF, 2002; TORALES, 2013).

No entanto, apesar da EA fazer parte dos currículos escolares, somente será efetivada, à medida que os(as) professores(as) reconhecerem sua importância em suas áreas de conhecimento e assumirem a responsabilidade de inclui-la em suas práxis educativa, sendo que a inserção da dimensão ambiental nas práticas escolares depende da interpretação feita pelos(as) professores(as) e suas reflexões sobre os aspectos socioambientais no meio em que estão inseridos (MEIRA CARTEA, 1993; SAUVÉ, 2001).

Para tanto, é preciso que os(as) professores(as) compreendam a complexidade da questão ambiental e suas implicações na vida cotidiana dos indivíduos, o que nos remete a compreender a relação entre a forma como os(as) professores(as) constroem seus saberes e os integram a sua prática docente, como elementos fundamentais para entender e repensar a inserção da EA no ensino formal. Nesse sentido, a EA ganha uma dimensão pedagógica no momento em que instituem espaços efetivos de questionamentos, encontros, confronto e negociação entre projeto político, universo cultural e interesses sociais diferentes, em que a ecopedagogia, como forma de fazer educação, tem a sustentabilidade como princípio educativo (GADOTTI, 2000).

Outro aspecto relevante na ação dos(as) professores(as) é o papel que exercem na composição de estratégias educacionais capazes de mobilizar a comunidade escolar em prol de ações socioambientais, tendo em vista que sobre seus ombros repousa a missão educativa da escola. Assim, trabalhar o conhecimento sob uma ótica de significado para a vida é desenvolver atitudes e habilidade congruentes para que o sentido de aprender possa reforçar o ideário da Educação Ambiental no círculo escolar.

No entanto, Tozoni-Reis (2008, p. 58) afirma que a EA no ensino formal é frequentemente tratada como iniciativa individual, como tema periférico das disciplinas, "são iniciativas muito tímidas, não existe preocupação oficial com 
a problemática ambiental no ensino superior”. De modo que são necessários esforços, na inserção da EA nos processos de formação de professores, que se articulem aos conteúdos críticos e reflexivos e que se pautem pela busca da autonomia, contribuindo para a apropriação de uma prática pedagógica autônoma e consistente, voltada as questões socioambientais no âmbito formal.

Por outro lado, é evidente que os avanços da EA na educação básica acabam responsabilizando os(as) professores(as), que são colocados diante de exigências às quais respondem com dificuldade e para as quais os cursos de formação inicial pouco contribuem. Além disso, Loureiro (2009) ressalta que as práticas pedagógicas que focalizam as questões ambientais mostram que os(as) professores(as) ainda não conseguiram superar a dicotomia entre teoria e prática, para tanto, é necessário considerar o conhecimento pré-existente dos alunos, como elementos fundamentais no processo pedagógico (FREIRE, 1996).

Diante deste quadro, pode-se afirmar que a EA está definitivamente incorporada à escola, embora de forma enfraquecida, fragilizada, inspirada ainda por uma concepção única e consensual. No entanto, a formação dos(as) professores(as), junto com outros elementos que atuam no contexto escolar, é parte do processo de incorporação do tema no âmbito curricular, pois, sem que haja uma compreensão das questões ambientais em seus aspectos políticos, ideológicos, culturais, sociais e econômicos, as ações tendem a se tornar descaracterizadas como alternativas para a renovação da prática pedagógica.

\section{Caminhos metodológicos}

$\mathrm{O}$ assentamento agroextrativista do Anauerapucu localiza-se na rodovia AP 070, a 16 km da sede do município de Santana no estado do Amapá e a 27 km da capital, estando à margem esquerda do rio Vila Nova, tem aproximadamente 235 domicílios e um total de 998 habitantes (IBGE, 2010). A comunidade não possui rede de esgoto, o que tem colaborado para que os dejetos humanos sejam jogados diretamente no rio Anauerapucu e nas bacias hidrográficas dos rios Vila Nova e Matapi, uma vez que as fossas negras estão localizadas às margens ou sob o rio, contribuindo para o aumento de doenças de vinculação hídrica.

Quanto ao atendimento educacional, a comunidade do Anauerapucu possui três escolas, sendo duas municipais, com oferta das séries iniciais $\left(1^{\circ}\right.$ ao $5^{\circ}$ ano), e uma estadual, a qual oferece Ensino Fundamental I e II ( $1^{\circ}$ ao $9^{\circ}$ ano) e Ensino Médio, onde foi desenvolvida esta pesquisa. No entanto, apesar das três escolas, Gomes et al. (2015) apontam que 12,6\% dos comunitários não são 
alfabetizados, reflexo da precariedade e da dificuldade de acesso à educação, o que tem contribuído para os baixos Índice de Desenvolvimento da Educação Básica (IDBE).

A Escola Estadual (EE) Francisco Filho que foi objeto de investigação desta pesquisa, oferta do Ensino Fundamental I e II no período matutino e o Ensino Fundamental II e Ensino Médio no turno vespertino. Em 2012 ofertou-se o Ensino Médio no período noturno, no entanto, devido às dificuldades com transporte e principalmente ao número elevado de gravidez precoce que, consequentemente, levavam a evasão, a escola, no ano seguinte (2013), deixou de ofertar esta modalidade de ensino no período noturno.

A EE Francisco Filho possui um quadro de 26 professores, sendo que somente 22 estão em atividade em sala de aula, os demais estão na biblioteca, na sala de leitura e na secretaria escolar. No corpo docente, há seis contratos administrativos (professores temporários) para as áreas em que há carência de profissionais, que são principalmente ciências biológicas e ciências exatas. De acordo com a coordenação pedagógica da escola, geralmente o ano letivo se inicia sem o elenco completo para atender os componentes curriculares, e, muitas vezes, os(as) professores(as) temporários só assumem no final do ano letivo, dificultando a manutenção de alguns projetos e o processo de ensino e aprendizagem.

Nesse contexto, esta pesquisa foi dividida didaticamente de forma que algumas etapas realizamos simultaneamente e outras imbricaram-se: 1) levantamento bibliográfico; 2) observação direta; 3) entrevistas semiestruturadas; e 4) sessões de grupo focal com os docentes da EE Francisco Filho.

No decorrer das entrevistas, solicitamos aos(as) professores(as) que abordassem sobre suas práticas educativas com a Educação Ambiental e como as integravam as suas áreas de conhecimento. Com base nesses dados, foi feito um roteiro a ser desenvolvido no método do Grupo Focal (GF), o qual, segundo Borges e Santos (2005), é uma dentre as várias modalidades disponíveis de grupo de discussão em que os participantes dialogam sobre um tema particular ao receberem estímulos apropriados para o debate.

Para execução da técnica do GF, dividimos os(as) professores(as) em dois grupos de trabalho, compostos por onze docentes cada, formados naturalmente de acordo com suas afinidades. Destacamos que apenas duas professoras pertenciam a comunidade de Anauerapucu, por esta razão, achamos que seria interessante, como fonte de informação específica, que cada uma ficasse em um grupo.

A primeira sessão teve início com uma breve introdução do moderador, situando os participantes dos objetivos do GF, os procedimentos a serem adotados, como o horário, o modo de condução, a presença de auxiliares, a gravação, as questões referentes ao sigilo das informações e a importância da participação 
de todos. Cada sessão durou aproximadamente $2 \mathrm{~h}$, e, no decorrer das discussões, foram feitos questionamentos aos participantes com a finalidade de compreender e esclarecer as percepções apresentadas pelo grupo.

Devido aos depoimentos que precisavam ser transcritos na íntegra, e, em seguida, a necessidade de categorizar as falas para podermos fazer um comparativo e para analisar cada item e situação colocada no decorrer da sessão I, extrapolamos o intervalo recomendado na técnica do GF, de no máximo 15 dias entre as sessões. Com este cuidado metodológico, no entanto, conseguimos ter uma visão mais aprofundada dos saberes dos(as) professores(as) pesquisados(as), assim como a síntese do pensamento coletivo, conforme propõe Fleck (2010). Portanto, consideramos que o espaço de mais de um mês entre as sessões foi essencial para o desenvolvimento de um trabalho mais preciso e consciente.

Para as análises qualitativas referentes às entrevistas com os(as) professores(as) e, posteriormente, às sessões de GF, valorizamos as falas individuais e coletivas. Dessa forma, foi possível traçarmos comparativos entre esses momentos da pesquisa, objetivando uma visão holística sobre a Educação Ambiental na práxis educativa.

\section{Resultados/discussão}

A EA no ambiente formal tem se configurado como uma tarefa fácil, segundo alguns estudos apontados por Tozoni-Reis et al. (2013), ao relacioná-la com as práticas na escola, embora essas atividades sejam consideradas fragmentadas, pontuais e prático-utilitaristas. Alguns autores (SILVA et al., 2010; DANTAS et al., 2012; SILVA et al., 2012) afirmam que as atividades em EA estão relacionadas apenas às datas comemorativas, como Dia Mundial da Água, Semana do Meio Ambiente, Dia da Árvore e, de acordo com o Prof. 10, "no passeio pro Museu Sacaca".

Partindo dessas premissas, verificamos que os(as) professores(as) da EE Francisco Filho não inserem a EA em suas práticas educativas, conforme os relatos a seguir:

Não, ainda não, mas até o fim do ano, quero trabalhar essa temática. Estou pensando de que forma eu posso trabalhar com eles, mas é meio complicado esse tema. (Prof. 01). 
Não, ainda não foi possível, é muita coisa que aconteceu durante o ano, e ainda não foi possível colocar isso, em sala de aula, e é muito complicado. (Prof. 02).

Sim, faço essa relação quando possível, em sala de aula e os livros às vezes nos ajudam, pois não temos tempo e nem materiais pra trabalhar a questão. (Prof. 03).

Aulas de conscientização que faço os alunos criarem e também uso a redação com eles, fazendo com que eles coloquem no papel o que entenderam. (Prof. 04).

Eu tento trazer algumas coisas que é daqui, mas falar sobre isso não. (Prof. 05).

Faço com que abranjam toda a sistemática com o meio em que a escola está localizada, acho isso fundamental. (Prof. 06).

Não, ainda não consegui fazer nada. Eu já tentei algumas vezes, até mesmo comentar com eles, mas não foi possível. (Prof. 08).

Os conteúdos que eu tenho passado eu não tenho usado a questão ambiental em si, ainda não tive um assunto que tratasse isso. (Prof. 09).

Só quando a gente faz os projetos. Que nem, por exemplo, nós tivemos um passeio pro Museu Sacaca que nós levamos os alunos que foi na disciplina Artes e Filosofia. (Prof. 10).

Não tem como fugir, né? Eu trabalho todos os temas da Educação Ambiental, lixo, água, poluição, tudo isso aí entra. (Prof. 11).

Eu trabalho desde o início do ano a questão ambiental. Em todas as salas eu detectava que iniciava limpinha, quando íamos finalizar, a questão do lixo era um transtorno. (Prof. 12). 
Só comentei algumas coisas nas aulas, mas não insiro, mas é importante fazer algo. (Prof. 14).

Não tive a oportunidade de trabalhar com esse assunto, mas com certeza vou ter. (Prof. 15).

De acordo com os relatos, podemos averiguar que a inserção da EA na prática educativa dos(as) professores(as) da EE Francisco Filho ainda não tem sido efetivada, sendo perceptível através das expressões "ainda não foi possível", "já tentei", "não tive um assunto", "não insiro", atribuindo à ausência de tempo para trabalhar, "não temos tempo", pois os(as) professores(as) consideram que a EA é um trabalho separado de suas disciplinas, requerendo mais tempo e dedicação para sua execução. Entretanto, reconhecem a importância da EA no cotidiano da sala de aula, como verificamos na expressão "mas é importante fazer algo", embora este fazer provavelmente se refira à coordenação pedagógica e aos(as) professores(as) de Ciências, Biologia e Geografia. Portanto, é visível a resistência dos(as) professor(as) da EE Francisco Filho em refletir sobre a inserção da EA no currículo escolar, fato este que tem dificultado sua efetivação na prática docente. Esta que não se resolve criando uma disciplina específica, mas tendo a participação da EA como atividade nuclear, o que nos remete ao papel dos(as) professores(as) na organização dos conteúdos escolares e na práxis educativa docente (TOZONI-REIS, 2012); considerando que o conjunto de práticas educativas, estreitaria as relações com a educação e suas tradições pedagógicas, com orientações específicas dentro da EA (SANTOS; SILVA, 2014; LIMA, 2015).

Outro ponto a ser comentado nas falas: dois(as) professores(as) usaram as expressões "não tive a oportunidade" e "os livros às vezes nos ajudam", esses relatos nos levam a compreender que, quando os(as) professores(as) discutem as questões ambientais em sala de aula, usam apenas os elementos contidos no livro didático, pois consideram que é a ajuda que possuem para desenvolver sua prática pedagógica. Enquanto outros(as) afirmaram não ter tido oportunidade de trabalhar a questão ambiental na sua disciplina, visto que os conteúdos curriculares dos livros das suas disciplinas não abordam essa temática, como bem lembram alguns autores (SILVA et al., 2012; SOUZA et al., 2014), o livro didático é a principal fonte de consulta nas escolas brasileiras.

Além disso, um(a) professor(a) afirmou necessitar de formação para trabalhar a EA em sua prática de sala de aula, afirmando que a EA precisaria ser uma disciplina ou que cada área de conhecimento tivesse um conteúdo no currículo 
específico voltado à questão ambiental, pois somente assim o(a) professor(a) poderia inseri-la em sua prática educativa. No entanto, embora a EA não seja necessariamente uma disciplina no currículo, o que é consenso nos estudos desse campo do conhecimento, não deixa de ser questionada por pesquisadores (TOZONI-REIS; CAMPOS, 2014) que se orientam por paradigmas mais complexos de organização da vida social e da educação escolar, ao considerarem que a EA deve ser inserida como um saber sistematizado, tendo um espaço nos currículos escolares.

Cabe um aparte para explicar porque a proposta de inserção da EA no currículo escolar vem se constituindo como um tema "periférico" e tendo um papel secundário nas atividades extracurriculares: "os sistemas educacionais estão, no Brasil, submetidos a tais e tantas pressões para atenderem a interesses de distintos agentes sociais, que a consequência geral não poderia ser outra senão o enfraquecimento da ação escolar" (CUNHA, 2011, p. 586). O enfraquecimento da ação escolar, apontado pelos(as) professores(as), inviabiliza o aprofundamento da EA na escola em uma perspectiva crítica, transformadora e emancipatória.

Além disso, os docentes em geral têm sido tratados pelas políticas públicas de EA como meros mediadores instrumentais dos conteúdos expressos nos recursos educativos, uma vez que as propostas de inserção curricular da EA pelos órgãos oficiais foram identificadas como intervenção de forças externas ao currículo da educação básica (CUNHA, 2011; TOZONI-REIS; CAMPOS, 2014).

Contreras (2002) ressalta, porém, que o papel dos(as) professores(as) é o da crítica permanente sobre a concepção de sociedade, de escola e de ensino, em sua prática docente, pautando-se no conhecimento teórico que problematiza as contradições e no conhecimento que orienta o processo educativo para a formação de cidadãos críticos.

Nesse sentido, é necessário que os(as) professores(as) tenham autonomia para conseguir a inserção da EA nas suas propostas educativas, considerando que está autonomia profissional é um processo contínuo de compreensão dos fatores que dificultam não só a transformação das condições sociais e institucionais do ensino, como também da própria consciência quanto educadores (CASTOR; TRISTÃO, 2015). Afirmamos que essas premissas vão além de levar aos(as) professores(as) os temas ambientais e suas possibilidades didático-pedagógicas, pelas atividades de formação permanente ou pelas propostas sistematizadas em nível das políticas públicas de EA, como realizamos nos grupos focais: implica em investir em estudos aprofundados das relações da educação com a sociedade e da sociedade com o ambiente na formação de professores(as).

Nessa perspectiva, Brito e Oliveira (2015) ressaltam que a prática didático-pedagógica deve favorecer o diálogo, no qual os educandos(as) também possam 
se sentir livres para expor seus pontos de vista, levando o sujeito a desenvolver sua criticidade em relação ao mundo, refletindo sobre suas ações no meio ambiente e, dessa forma, contribuindo para mudanças significativas no âmbito local, regional e mundial. Este entendimento já foi exposto em vários momentos desta pesquisa.

Os saberes dos educandos devem servir de base para a construção da prática docente, considerando as peculiaridades existentes no contexto da sala de aula, pois é neste ambiente que são consolidados e surgem como núcleo vital do saber docente o diálogo, pois é na sala de aula que suas ações podem mostra um caminho seguro a ser seguido, mas também pode significar a cegueira no que diz respeito aos pontos falhos de sua prática (TARDIF, 2002; TOZETTO, 2011).

Souza et al. (2014, p. 40) complementam que quando os(as) professores(as) planejam aulas "na perspectiva da interdisciplinaridade, propiciam uma aprendizagem significativa, quando levam em consideração conhecimentos prévios e nas quais os alunos têm a oportunidade de compartilhar dúvidas, opiniões e, literalmente, manusear neste processo, para construir respostas vinculadas às apreensões dos conteúdos abordados".

Verificamos que dos(as) quatros professores(as) da área de Ciências Biológicas, dois disseram que não conseguiram trabalhar com EA, mas pretendem. Os outros dois: "faço os alunos criarem e também uso a redação" (Prof. 04) e "Eu tento trazer algumas coisas que é daqui" (Prof. 05), mas não detalharam, demonstrando que a concepção de que EA deve ser tarefa das Ciências Biológicas não se aplica nas práticas educativas. Os(as) professores(as) das Ciências Exatas (profs. 06 a 08) também não conseguiram expor o que fazem em suas práticas, embora o Prof. 06 tenha comentado: "Faço com que abranjam toda a sistemática com o meio em que a escola está localizada". Dos(as) professores(as) das Ciências Humanas (profs. 09 a 22), apenas um(a) professor(a) da área de Humanas desenvolve a EA em sua prática didático pedagógica, conforme relato a seguir:

Eu trabalhei usando quadrinhos. Tem um livro da turma da Mônica e tem vários temas, relacionados à água, ao lixo, à mudança na Amazônia, às florestas, tudo, nesses quadrinhos! Então a disciplina inteira eu trabalhei com base nos quadrinhos, só que assim, eles faziam a leitura e eu fazia as atividades em cima da leitura e interpretação dos quadrinhos. Trabalhei também com encenação, com teatro, que por sinal eles apresentaram muito bem, foi muito legal. Assim, a culminância, eles se esforçaram: fizeram até paródia, escrevendo paródia e trabalhei várias dinâmicas também ligadas ao tema, por exemplo, água, é, a gente trabalhou a confecção de quadrinhos, como se fosse um rio. Eles mesmo produziram, e, tudo, em desenho. Eles produziram também quadrinhos, em cima do que a gente já tinha. (Prof. 13). 
Verificamos no relato as expressões "água", "lixo", "florestas", dentre outras, que, mesmo quando a EA é discutida na prática educativa do (a) Prof. 13 (Geografia), não contempla a complexidade socioambiental, prevalecendo os recursos naturais sem a relação estabelecida do homem com a sociedade. No entanto, percebemos o esforço deste(a) professor(a) para a efetivação da EA em sua prática educativa, embora ainda não tenha conseguido compreendê-la além dos problemas ambientais vigentes. Este fato também foi constatado, quando os(as) professores(as) afirmaram inserir a EA na sua prática docente, mas percebemos ser fragmentada, pois estão diretamente ligadas aos problemas ambientais da escola e/ou comunidade de Anauerapucu. Isto evidencia que não temos conseguido, por um lado, inserir o tema ambiental no currículo escolar de forma inovadora e, por outro, não temos conseguido potencializar o caráter crítico dos temas ambientais que emergem das contradições das sociedades, sob o modo de produção capitalista. Mas esses dados não nos surpreendem, pois estudos apresentados por Cruz e Bigliardi (2012) e por Tozoni-Reis e Campos (2014) têm trazido indicadores das dificuldades dos professores em inserir a EA no âmbito escolar, sendo perceptível nos relatos dos(as) professores(as) da EE Francisco Filho, ao serem indagados sobre a responsabilidade da EA na prática educativa escolar:

Envolve todas as disciplinas, dá pra se trabalhar em todas as áreas. (Prof. 01).

Ciências, História e Geografia são disciplinas que podem ser relacionadas, pois elas são matérias que falam e que são mais parecidas com esse tema. (Prof. 02).

Na verdade, eu acho que não tem uma disciplina a ser trabalhada, ela é trabalhada de uma forma transversal, então, ela é inserida no todo. (Prof. 03).

Todas as disciplinas e mais um pouquinho, só que é preciso distribuir como se trabalhar, mas em todas as matérias é possível sim. (Prof. 04).

Em todas as disciplinas, porque o meio ambiente, é muito importante e precisa ser tratado. (Prof. 05). 
Talvez deva ter alguma forma de trabalhá-la na minha disciplina. Mas acho que mais na área de humanas e linguagens. (Prof. 06).

Geografia e Biologia, pois são disciplinas afins, e que realmente podem se trabalhar em conjunto com essa temática. (Prof. 08).

Geografia e História. Acho que essas seriam as principais. (Prof. 09).

Eu acho que em Sociologia e em Arte também pode trabalhar. (Prof. 10).

Tem que ser trabalhada em todas, porque a Educação Ambiental é um problema que ela atinge todo mundo. (Prof. 11).

Ciências, Biologia, Geografia, História. Porque são as que, além das aulas serem poucas, os conteúdos falam muito sobre esse tema. (Prof.12).

Pra mim seriam: Ciências, Biologia, Geografia. Meio ambiente vem pela Ciências e pela Geografia também. Os professores dessas disciplinas é que deveriam ser mais alertados, atentos a que passar nesse conteúdo. (Prof.13).

Na verdade, deveriam ser todas, mas parece que é uma coisa que fica mais especifica pra Ciências, mas a Matemática, a meu modo, não combina. (Prof. 14).

Acho que Geografia, História. Não dá pra ser trabalhado só em uma matéria. Fica dificil eu falar de História sem tocar na questão ambiental, de Biologia, Física e a própria Arte! Se eu vivo aqui. (Prof. 15).

Não consigo pensar em nada que trate em si a questão ambiental na minha disciplina. Já a Geografia e a Ciência sim. Na verdade, deveria se todos, mas, parece que é um conteúdo mais específico pra Ciências, mas, Matemática não combina, mas melhor seria se fosse em todas. (Prof. 20). 
Eu acho que não existe só uma não, nem duas. É um tema muito abrangente e mesmo porque é o dia a dia do aluno. (Prof. 21).

Em todas as disciplinas, basta adaptar, de que maneira esse professor vai trabalhar, e acredito que na prática. (Prof. 22).

Percebemos que na expressão "na verdade, deveriam ser todas", os(as) professores(as) embora tenham clareza de que a EA deveria ser inserida em todas as disciplinas, reconhecem que não a trabalham em suas áreas de conhecimento, pois acreditam ser responsabilidade de outros(as) professores(as): "pra mim seria Ciências, Biologia, Geografia" e também "História", simplificando a inserção da EA na prática educativa, através de expressões simplórias como: "eu acho", fato este que reafirma estudos presentes na literatura ao relatarem que, de modo geral, os docentes atribuem a responsabilidade da EA a esses profissionais. Inclusive, um(a) professor(a) foi mais enfático quanto às disciplinas que reconhecidamente devem abortar a EA: "professores dessas disciplinas é que deveriam ser mais alertados, atentos a que passar nesse conteúdo".

No entanto, verificamos no relato de um(a) dos(as) professores(as) a expressão “o dia a dia do aluno", em que fica evidente que apesar de apresentarem pouco interesse pela temática, eles(as) reconhecem que deveriam considerar a realidade cotidiana do educando para trabalhar a EA, acreditando que o modo de vida do alunado está diretamente ligado à natureza e, portanto, deveria ser inserido na adequação curricular. Portanto, propomos que seja ofertado aos(as) professores(as) da EE Francisco Filho um curso de formação continuada pela gestão pública, que eles(as) já solicitaram em suas falas. No GF percebemos que esta demanda é preenchida, para que assim possam compreender a complexidade da EA e principalmente as adequações curriculares para atender as especificidades de escolas ribeirinhas da Amazônia amapaense, assim como compreender sua efetivação na práxis educativa, inter-relacionando teoria e prática. Partindo desse pressuposto, Freitas (2005) afirma que, na complexidade desse processo, faz-se necessário resgatar na prática docente o caráter de práxis, através da unidade entre o teórico e o prático, superando a simplificação do prático-utilitário que tem impedido os(as) professores(as), no exercício de sua função de construir uma contraposição ao "praticismo".

Considerarmos que a teórica e a prática caminham juntas, uma vez que a teoria esclarece e enriquece a prática, dando novas significações e mais! que o sucesso da ação prática visa à transformação social. Portanto, a teoria não é apenas uma justificativa da prática, mas influencia o desenvolvimento de práti- 
cas transformadoras, assim, uma prática sem teoria não ultrapassa a barreira do senso comum, tornando-se apenas "praticista" (VAZQUEZ, 1990).

No caso da EA, o conhecimento desenvolvido pelos(as) professores(as) deve aprofundar as conexões com a difusão de temas e de conceitos. Assim, no ambiente escolar, os(as) docentes têm buscado o desenvolvimento de valores, atitudes e comportamentos, que considerem a relação entre sociedade e natureza, salientando que a EA encontra interface na habilidade dos professores em desenvolverem meios de ensinar, atividade por si só complexa e sujeita a situações inesperadas (MENDES; VAZ, 2009).

Nesse sentido, Shulman (1986) ressalta que os saberes dos(as) professores(as) devem servir de base para a escolha teórica de determinado conhecimento a ser repassado, com o uso de proposições, casos ou dilemas vividos em sua prática, o que influencia diretamente o modo como o conhecimento será transmitido em sala de aula.

Além disso, Mendes e Vaz (2009) verificaram que focar o ambiente como tema de trabalhos é uma boa maneira de inserir a EA no cotidiano da escola, porque o(a) professor(a) pode se utilizar de estratégias pedagógicas para informar o aluno não só dos conhecimentos específicos da sua disciplina, mas também de outros voltados à EA holística, com a participação ativa do seu alunado. Assim, a realidade dos(as) professores(as) da EE Francisco Filho, a natureza e o modo de vida dos educandos são recursos didáticos pedagógicos extraordinários a serem considerados na práxis educativa docente, atrelando as especificidades regionais amazônicas ao saber fazer no cotidiano escolar, rompendo, assim, com o paradigma predominante de que a EA se restringe apenas aos problemas ambientais e às medidas a serem tomadas estariam restritas a ações isoladas de reciclagem e reaproveitamento de material.

\section{Conclusões}

Embora, os(as) professores(as) tenham ressaltado que é inevitável o medo da mudança e de implantação de projetos e atividades que insiram a EA em suas práticas educativas, pois as experiências anteriores, em outras escolas, mostraram que é muito trabalhoso e requer tempo para a inserção nas atividades curriculares. Isso mostra que não temos conseguido, por um lado, inserir o tema ambiental no currículo escolar de forma inovadora e, por outro, não temos conseguido potencializar o caráter crítico dos temas ambientais que emergem das contradições da sociedade. 
No entanto, a partir das trocas de saberes, percebemos que os(as) professores(as) começaram a fazer grupos de trabalho para inserir a EA em suas áreas de conhecimento em parceria com professores(as) de outras áreas, acarretando na exibição de cine ambiental, de projetos interdisciplinares entre os turnos matutinos e vespertinos, como, por exemplo, a feira da reutilização e o projeto horta que foram implementados na EE Francisco Filho como fruto da pesquisa desta pesquisa.

\section{REFERÊNCIAS}

BORGES, C. D.; SANTOS, M. A. Aplicações metodológicas da técnica de Grupo Focal: fundamentos metodológicos, potencialidades e limites. Revista SPAGESP, v. 6, n. 1, p. 74-80, 2005.

BRITO, R. A. de; OLIVEIRA, G. F. de. A prática dialógica argumentativa nas aulas de educação socioambiental. Revista Eletrônica do Mestrado em Educação Ambiental, Dossiê Educação Ambiental, edição especial, p. 71-83, 2015.

CARVALHO, I. C. M. Educação Ambiental: a formação do sujeito ecológico. 1. ed. São Paulo: Cortez, 2012.

CASTOR, K. G.; TRISTÃO, M. Gira-mundos: a educação ambiental no mito e o mito na educação ambiental. Revista Eletrônica do Mestrado em Educação Ambiental, v. 32, n. 1, p. 172-188, 2015.

CONTRERAS, J. A autonomia de professores. 1. ed. São Paulo: Cortez, 2002.

CRUZ, R. G.; BIGLIARDI, R. V. Uma abordagem exploratória ao conteúdo epistemológico das diretrizes curriculares nacionais para educação ambiental. Revista Eletrônica do Mestrado em Educação Ambiental, v. 29, p. 1517-1256, jul./dez. 2012.

CUNHA, L. A. Contribuição para a análise das interferências mercadológicas nos currículos escolares. Revista Brasileira de Educação, v. 16, n. 48, p. 585-809, 2011.

DANTAS, O. dos S.; SANTANA, A. R.; NAKAYAMA, L. Teatro de fantoches na formação continuada docente em Educação Ambiental. Educação e Pesquisa, São Paulo, v. 38, n. 3, p. 711-726, 2012.

FLECK, L. Gênese e desenvolvimento de um fato científico. 1. ed. Belo Horizonte: Fabre Factum, 2010.

FREIRE, P. Pedagogia da autonomia: saberes necessários à prática educativa. 1. ed. São Paulo: Paz e Terra, 1996. 
FREITAS, M. A. Práxis pedagógica e professores intelectuais: refletindo as tensões e concepções da formação/prática docente. Práxis Educacional, v. 1, n. 1, p. 135-150, 2005.

GADOTTI, M. Pedagogia da terra. 1. ed. São Paulo: Petrópolis, 2000.

GOMES, R. K. S.; SILVA, M. do C. L.; MEDEIROS, M. M. A sustentabilidade da educação socioambiental no Assentamento do Anauerapucu, Amazônia Amapaense. Revista Eletrônica do Mestrado em Educação Ambiental, v. 32, n. 1, p. 329-343, 2015.

GUIMARÃES, M. A formação de educadores ambientais. 1. ed. São Paulo: Papirus, 2011.

INSTITUTO BRASILEIRO DE GEOGRAFIA E ESTATÍSTICA (IBGE). Censo das cidades. Brasília, 2010. Disponível em: < http://www.ibge.gov.br/cidades $>$. Acesso em: 30 jan. 2017.

LEFF, E. Discursos sustentáveis. 1. ed. São Paulo: Cortez, 2010.

LIMA, N. L. A teoria social no pensamento de Paulo Freire: uma análise do livro "Pedagogia do oprimido". In: AMORIN, A. S. et al. Teorias, ensino, aprendizagem: revisitando pensadores da educação. São Paulo: Paco, 2015.

LOUREIRO. C. F. B. Mundialização do capital, sustentabilidade democrática e políticas públicas: problematizando os caminhos da educação ambiental. Revista Ambiente e Educação, v. 14, p. 11-22, 2009.

MEIRA CARTEA, P. A. A educación ambiental e a reforma educativa. Revista Galega de Educación, Vigo: Nova Escola Galega, n. 18, 1993.

MENDES, R.; VAZ, A. Educação ambiental no ensino formal: narrativas de professores sobre suas experiências e perspectivas. Educação em Revista, v. 25, n. 3, p. 395-411, 2009.

SANTOS, R. J. dos; SILVA, L. F. da. A temática ambiental presente nos manuais dos(as) professores(as) dos livros didáticos de Biologia aprovados no PNLD 2012. Revista Eletrônica do Mestrado em Educação Ambiental, v. 31, n. 2, p. 296-311, 2014.

SAUVÉ, L. Éducation et environnement à l'école secondaire: modèles d'intervention en éducation relative à environnement développés par. Montreal, Quebéc: Les Éditions Logiques, 2001.

SHULMAN, L. Those Who Understand: knowledge growth in teaching. Educational Researcher, v. 15, n. 2, p. 4-14, 1986.

SILVA, F. S.; OLIVEIRA, G. M. de; SILVA, L. J. da; CONCEIÇÃO, L. C. da; NAKAYAMA, L., SANTANA, A. R. de. Educação Ambiental: olhares e propostas no município de Rondon do Pará. Revista Eletrônica do Mestrado em Educação Ambiental, v. 24, p. $1-11,2010$.

SILVA, L. C. da; CONCEIÇÃO, L. C. da; SANTANA, A. R.; NAKAYAMA, L. Projeto Sábado Esperto: Educação Ambiental no Bosque Rodrigues Alves - Jardim Botânico da Amazônia, Belém - PA. Educação Ambiental em Ação, n. 40, p. 1-15, 2012. 
SOUZA, S. S. P.; SANTANA, A. R.; NAKAYAMA, L. Aprendizagem significativa no ensino de ciências: o sistema locomotor no cotidiano dos estudantes. Dynamis, v. 20, n. 1, p. 39-53, 2014.

TARDIF, M. Saberes docentes e formação profissional. 2. ed. Petrópolis: Vozes, 2002.

TEIXEIRA, C.; TORALES, M. A. A questão ambiental e a formação de professores para a educação básica: um olhar sobre as licenciaturas. Educar em Revista, edição especial, n. 3, p. 127-144, 2014.

TORALES, M. A. A inserção da educação ambiental no currículo escolar e o papel dos(as) professores(as): da ação escolar a ação educativa-comunitária como compromisso político ideológico. Revista Eletrônica do Mestrado em Educação Ambiental, v. esp., p. 1-15, 2013.

TOZETTO, S. S. Os saberes da experiência e o trabalho docente. Revista Teoria e Prática da Educação, v. 14, n. 3, p. 17-24, 2011.

TOZONI-REIS, M. F. C. Educação ambiental: natureza, razão e história. 2. ed. São Paulo: Autores Associados, 2008.

TOZONI-REIS, M. F. C. Educação ambiental na escola básica: reflexões sobre as práticas dos(as) professores(as). Revista Contemporânea de Educação, v. 7, n. 14, p. 276-288, 2012.

TOZONI-REIS, M. F. C. et al. A inserção da educação ambiental na educação básica: que fontes de informação os(as) professores(as) utilizam para sua formação? Ciência da Educação, v. 19, n. 2, p. 359-377, 2013.

TOZONI-REIS, M. F. C.; CAMPOS, L. M. L. Educação ambiental escolar, formação humana e formação de professores: articulações necessárias. Educar em Revista, edição especial, n. 3, p. 145-162, 2014.

VAZQUEZ, A. S. Filosofia da práxis. 4. ed. Rio de Janeiro: Paz e Terra, 1990.

Texto recebido em 09 de fevereiro de 2017. Texto aprovado em 14 de abril de 2017. 
